used in many places; but the occurrence related by my patient was the first example of this use of music about which I have heard.

It would be interesting to hear if others have tried the use of music in this way and, if so, whether it is thought to have given significant satisfaction and relief of anxiety to patients.

\section{JOHN LUCEY}

Hockering,

Woking, Surrey

\section{Clinical rheumatology}

SIR,-Clinical rheumatology may have advanced, but Dr A St J Dixon (16 April, p 1015), while making some comments about rehabilitation with which many would agree, singularly fails to progress the discussion about what clinical rheumatologists should do. Like Professor W W Buchanan (11 September 1976, p 628) he works in a specialised unit serving a large population and from this intense but restricted experience generalises about what is needed in a district general hospital. As one who works in a district general hospital in an area generously endowed with rheumatologists I find it difficult to recognise the picture he paints.

Discussions about rheumatology are bedevilled by varying estimates of the prevalence of rheumatoid arthritis, most of which are based on criteria ${ }^{1}$ " which almost certainly overestimate the amount of clinically significant disease-for example, the British League against Rheumatism has two current publications quoting prevalence rates of $1 \%$ and $1 \%$ and $2 \%{ }^{4}$ The confusion is well illustrated by the Sudbury report, ${ }^{j}$ which revealed a prevalence of probable or definite rheumatoid arthritis of $2.5 \%$ using the old criteria" and of $0.35 \%$ using the much more stringent 1966 New York criteria."

If the Sudbury experience using the New York criteria is projected on to a moderatesized district general hospital serving a population of 150000 it suggests that in this group there would be only 500-550 patients with rheumatoid arthritis. At least half of these would have only mild or moderate involvement, and when one considers that all the other generalised rheumatic diseases combined form a smaller problem than rheumatoid arthritis itself it can be seen that at such a hospital there is no major career to be made out of looking after "rheumatoid arthritis and its complications and those diseases that resemble it in some way."

Mechanical and degenerative disorders of the locomotor system are the commonest rheumatic problems - the field of orthopaedic medicine-and one of the major problems of clinical rheumatology is to decide who should look after these patients in hospital. If orthopaedic surgeons abound one of the solutions proposed by Dr Dixon of a person combining internal medicine and rheumatology who would deal primarily with polyarthritis may be an excellent answer, though as internal medicine will itself always be a demanding discipline there may be a danger of creating a number of consultants for whom rheumatology is only a second interest. If orthopaedic surgeons are scarce then there may be a useful role for the rheumatologist who tackles both orthopaedic medicine and polyarthritis.

There is no clear solution and geographical factors will always play an important role in delineating some appointments. None the less, using the district general hospital concept we need more discussion about what type of rheumatologist is required there and in particular what the relationship to orthopaedics should be. Without this discussion we know neither how many rheumatologists are needed nor how best to train them.

\section{Peter Blower}

Greenwich District Hospital,

London SE10

' Ropes, M W, et al, Bulletin on Rheumatic Diseases, $1958,9,175$

Kellgren, J H, Bulletin on Rheumatic Diseases, 1962,

13, Challenge of Arthritis and Rheumatism, British

Rheutism, the Price We Pay, British League against Rheumatism, 1977.

fournal, E S, and O'Sullivan, J B, New England Fournal of Medicine, 1970, 282, 421 . Bennett, P H, and Burch, T A, Bulletin on Rheumatic
Diseases. 1967, 17, 453.

\section{Cimetidine in alleviation of gastric cancer pain}

SIR,-We have noted significant pain relief in two patients with malignant gastric ulcers who have been treated with cimetidine.

The first patient, a man aged 63, was referred with a history of dvspepsia for several years which had become worse in the previous three months. Barium meal confirmed the clinical diagnosis of a $1.5-\mathrm{cm}$ lesser-curve gastric ulcer. Cimetidine $200 \mathrm{mg}$ thrice daily and $400 \mathrm{mg}$ at night was started. When the patient attended for gastroscopy three weeks later he reported complete relief of his pain. At endoscopy the mucosa was growing into the ulcer, which was obviously healing. Biopsy showed adenocarcinoma. Subtotal gastrectomy was subsequently performed.

The second patient, a man aged 66 , was referred with severe epigastric pain due to carcinoma of the stomach with liver secondaries. The diagnosis was confirmed histologically by endoscopy. Laparoscopy confirmed the clinical impression that palliative surgery was not feasible. Cimetidine $200 \mathrm{mg}$ thrice daily and $400 \mathrm{mg}$ at night resulted in significant relief of pain after seven days.

We consider that the symptomatic relief of pain in malignant gastric ulcer by cimetidine can be misleading and emphasises the need for endoscopic and histological assessment of gastric ulcers, but that this drug is a useful addition for the clinician in the relief of pain from gastric cancer.

C L WELSH

J L Craven

York District Hospital, DAvid HoPTON

York
York

\section{Thyroid function tests and oral} contraceptives

SIR,-The paper by Dr W A Burr and others (19 February, $p$ 485) has shown that the derived free thyroxine index (FTI) may give fallacious results in certain groups of patients.

We have been interested in the measurement of thyroid function during the ovulatory cycle in normal women and in women taking ora contraceptives. Serum total thyroxine (T4) was measured by a radioimmunoassay method based on that of Challand et al. ${ }^{1}$ Triiodothyronine (T3) uptake was measured by a commerical kit method (Thyopac-3, Radiochemical Centre, Amersham). The FTI was calculated for each sample. Serum T4 and serum $\mathrm{T} 3$ uptake were measured on the 5 th and 20th days of the ovulatory cycle of 20 women (controls). The FTI (T4/T3 uptake) was calculated from these determinations. Serum T4 and T3 uptake were measured on the 20th day of the cycle of 20 women taking Minilyn (lynoestrenol $2.5 \mathrm{mg}$ and ethinyloestradiol $0.05 \mathrm{mg}$ )

There was no significant difference between T4, T3 uptake, and FTI between the samples taken on the 5 th and 20 th days of the ovulatory cycle of the control group. Comparison of the FTI between the control group and those patients receiving Minilyn showed a highly significant increase in the FTI $(\mathbf{P}<0.0001$ using the Mann Whitney test) in the patients on oral contraceptives (see table). However, while there was good correlation $(r=0.82)$ between the T3 uptake and serum $\mathrm{T} 4$ in the control group on the 20th day of the cycle, in the patients taking Minilyn the correlation between these two values on the 20 th day was very poor $(r=0 \cdot 15)$

Derived free thyroxine index in controls and patients taking Minilyn

\begin{tabular}{|c|c|c|c|}
\hline & \multicolumn{2}{|c|}{ Controls } & \multirow{2}{*}{$\begin{array}{c}\text { Oral } \\
\text { contraceptive } \\
\text { group (20th day }\end{array}$} \\
\hline & 5 th day & 20th day & \\
\hline $\begin{array}{l}\text { Mean } \\
\text { Standard deviation } \\
\text { Range }\end{array}$ & $\begin{array}{r}87 \cdot 35 \\
8 \cdot 25 \\
76-99\end{array}$ & $\begin{array}{l}83 \cdot 4 \\
10 \cdot 22 \\
61-98\end{array}$ & $\begin{array}{c}111 \cdot 55 \\
22 \cdot 74 \\
70-163\end{array}$ \\
\hline
\end{tabular}

This suggests that the use of the calculated FTI using the Thyopac-3 method can give falsely high results in patients taking Minilyn.

O DJaHANBaKHCH

Chelsea Hospital for Women, London SW3

T HARGREAVES

Area Department of Pathology,

D W SYKES

Royal Devon and Exeter Hospital,

Heavitree, Devon

Challand, G S, Ratcliffe, W A, and Ratcliffe, J G Clinical Chimica Acta, 1975, 60, 125.

\section{Appendicitis and diabetes}

SIR,-Professor J P Corridan and his colleagues report (30 April, p 1135) that they found no association between appendicitis and diabetes in individual patients. They assume that since both of these diseases have been attributed to the refining of carbohydrate foods such an association was to be expected.

Their failure to find an association in no way invalidates the hypothesis that these diseases share common causative factors. Appendicitis has been attributed to the increased viscosity of faeces caused by loss of water from the colon resultant on loss of fibre from the diet. Diabetes on the other hand has been related to increased consumption and increased rate of absorption of starch and sugar stripped of their natural fibre packing.

It is possible to increase sugar intake considerably while consuming a diet with adequate fibre to maintain a large soft faecal volume. A friend of mine with 35 years' experience as a medical missionary in Africa saw diabetes appear in his area after the introduction of sugar and sweetened drinks and over 20 years later saw the cessation of new cases when these commodities became no longer obtainable. He saw no case of appendicitis in an African during this time. 